\section{TÀI LIÊU THAM KHẢO}

1. Alberti KGMM, Zimmet PZ. Definition, diagnosis and classification of diabetes mellitus and its complications. Part 1: diagnosis and classification of diabetes mellitus. Provisional report of a WHO Consultation. Diabetic Medicine. 1998;15(7):539-553.

2. Hartling $L$, Dryden DM, Guthrie $A$, et al. Screening and Diagnosing Gestational Diabetes Mellitus. Agency for Healthcare Research and Quality (US); 2012.

3. Nguyến Lế Hương, Đỗ Quan Hà. Tỷ lệ đái tháo đường thai nghén tại khoa Khám theo yêu câu, Bênh viện Phụ Sản Trung Ương năm 2012 và một sổ yếu tố nguy cơ. Tạp chí Phụ Sản. 2014;12(2):108-111.

4. Lê Thi Thanh Tâm. Nghiên Cứu Phân Bố Một Số Yếu Tổ Liên Quan và Kểt Quả Sản Khoa ở Thai Phu Đái Tháo Đường Thai Kỳ Tại Thành Phố Vinh. Luận Án Tiến sỹ Y Học.; 2017.

5. HAPO Study Cooperative Research Group,
Metzger BE, Lowe LP, et al. Hyperglycemia and adverse pregnancy outcomes. N Engl J Med. 2008;358(19):1991-2002.

6. Lê Thi Thanh Tâm, Đặng Thị Minh Nguyêt, Nguyển Cảnh Phú. Nhận xét kết quả xét nghiếm sàng loc bênh đái tháo đường thai kỳ tai thành phố Vinh, Nghệ An. Tạp chí $Y$ học thực hành. 2016:997(2/2016):124-126.

7. Vũ Bích Nga. Nghiên Cứu Ngưỡng Glucose Máu Lúc Đói Để Sàng Loc Đái Tháo Đướng Thai Kỳ và Bước Đầu Đánh Giá Hiệu Quả Điều Trị. Luận án Tiến sĩ Y Học, Trường Đại Học Y Hà Nội.; 2009.

8. Crowther CA, Hiller JE, Moss JR, et al. Effect of treatment of gestational diabetes mellitus on pregnancy outcomes. N Engl J Med. 2005;352(24):2477-2486.

9. Hirst JE, Tran TS, Do MAT, Morris JM, Jeffery HE. Consequences of gestational diabetes in an urban hospital in Viet Nam: a prospective cohort study. PLoS Med. 2012;9(7):e1001272.

\title{
THỰC TRANG TIẾNG ÔN VÀ THỰC HÀNH PHÒNG NGỪA ĐIẾC NGHỀ NGHIÊPP CỦA NGƯỜI LAO ĐÔ̂NG TẠI NHÀ MÁY TINH BộT SẮN ĐỒNG XUÂN, PHÚ YÊN, 2018
}

\section{TÓM TẮT}

Một trong những bệnh nghề nghiệp có xu hướng ngày càng gia tăng tỷ lệ thuận theo tốc độ hiện đại hóa - công nghiệp hóa của xã hội hiện nay là bệnh điếc nghề nghiệp. Hầu hết các quy trình sản xuất đều phát ra tiếng ồn, tuy nhiên, một số ngành nghề đặc thù có mức ồn cao tập trung chủ yếu ở các ngành sản xuất công nghiệp, in ấn, xay xát và chế biến thực phẩm. Nghiên cứu đã đước tiến hành với muc đích tìm hiểu mức độ ô nhiễm tiếng ồn tại nhà máy và thực hành của người lao động tai đây trong viêc phòng ngừa điếc nghề nghiệp. Nghiên cứu mô tả cắt ngang đã được tiến hành khảo sát trên 125 công nhân tham gia lao động trực tiếp tại nhà máy. Thực hiện quan trắc tổng số mấu về tiếng ôn là 64 , trong đó tiếng ôn chung là 40 mẫu và tiếng ôn theo dải tần là 24 mẫu. Kết quả nghiên cứu cho thây có $53,9 \%$ mấu tiếng ôn vượt giới hạn cho phép; cường độ tiếng ồn chung tại nhà máy dao động trong khoảng $74-93$ dBA; khu vực phát ra tiếng ồn cao nhất là khu vực phân ly với mức ồn trung bình là $91 \pm 1,83$ dBA.Tuy nhiên, chỉ có $52,8 \%$ người lao động có thực hành đúng trong việc phòng ngữa điếc nghề nghiệp. Đáng lưu ý là chỉ có 44\% người lao động sử dụng thiết bị bảo hộ lao động

\footnotetext{
${ }^{1}$ Trường Đại học Y tế công cộng

${ }^{2}$ Trung tâm kiểm soát bệnh tật tỉnh Phú Yên

Chịu trách nhiệm chính: Nguyễn Ngọc Bích

Email: nnb@huph.edu.vn

Ngày nhận bài: 9.3.2021

Ngày phản biên khoa hoc: 28.4.2021

Ngày duyệt bài: 12.5 .2021
}

\section{Nguyễn Ngọc Bích ${ }^{1}$, Phan Thị Lan Phương ${ }^{2}$}

một cách thường xuyên khi tiếp xúc với nguồn ồn và chỉ có $31,5 \%$ công nhân đeo thiết bị bảo vệ tai đúng cách khi làm việc. Nghiên cứu khuyến nghị nhà máy áp dụng các giải pháp giảm thiểu tiếng ồn nơi làm việc và giám sát việc sử dụng thiết bị bảo hộ cá nhân của người lao động.

Tư khoá: tiếng ôn, nhà máy chế biến thực phẩm, thực hành phòng bệnh, điếc nghề nghiệp

\section{SUMMARY NOICE INDUCED AT WORK AND PREVENTION PRACTICE AMONG WORKERS AT A FOOD PROCESSING COMPANY IN PHU YEN}

Hearing loss is one of the most common occupational health issues in the world and in Vietnam. Sectors that have working environment polluted with were mining, gridding and food processing. This study aimed to investigate the situation at a food processing company and prevention practice among workers. The cross sectional study was conducted in 125 workers of the company 64 environment samples were collected among them 40 were for general noise and 24 for different octave ranges. Results show that $53.9 \%$ of environmental samples exceeded the national limit, it range from $74-93 \mathrm{dBA}$; section with highest noise level was separating section with noise level $91 \pm$ 1,83 dBA.Only $52.8 \%$ practice adequately on hearing loss prevention. Only $44 \%$ of woekers used PPE frequently, and only $31,5 \%$ used headset to protect their ears. It was recommended that the company should apply measures to reduce noise level at workd and supervise workers on using PPE while working. 
Keywords; noise, food processing, disease prevention, occupational hearring loss

\section{I. ĐĂT VẤN ĐỀ}

Một trong những yếu tố nguy cơ cho người lao động là điếc nghề nghiệp (ENN) do lao động trong môi trường thường xuyên tiếp xúc với tiêng ồn trong dây chuyền sản xuất của nhà máy tại các khu công nghiệp $(1,2)$

Theo báo cáo của Viện Sức khỏe nghề nghiệp và môi trường quốc gia, tính đến tháng 12/2015, cả nước có 5.099 trường hợp điếc liên quan đên nghề nghiệp (tăng 265 trường hợp so với năm 2014), chiểm 17,6\% trong tổng số bệnh nghề nghiệp và là một trong hai bệnh nghề nghiệp phổ biến nhất tại Việt $\operatorname{Nam}(3)$ Theo kết quả nghiên cứu mới nhất về những "bệnh bùng phát toàn cầu" (Global Burden of Disease) cho thấy tình trạng giảm thính lực đang tăng lên và hiện đang ở mức báo động $(4,5,6)$. Tại Hoa kỳ, ĐNN là bệnh lý mãn tính liên quan đển nghề nghiệp đứng thứ 3 sau các bệnh ung thư và tiểu đường. Có khoảng 22 triệu công nhân (CN) Mỹ bị phơi nhiễm với tiếng ồn, trong đó nguyên nhân tiếng ôn từ ngành công nghiệp sản xuất thực phẩm đứng thứ ba sau các ngành khai thác mỏ và xây dựng. Theo tổng cục thônng kê lao động Hoa Kỳ thì hầu hết các ngành công nghiệp thực phẩm và đồ uống có các quy trình phát ra tiếng ồn cao hơn mức $85 \mathrm{~dB}$. Ví dụ mức độ tiếng ồn phát ra trong các ngành công nghiệp bánh mỳ, sữa và bánh kẹo khoảng 85 - 95dB nhưng mức độ này sẽ tăng lên $100 \mathrm{~dB}$ tại các nhà máy xay xát (7). Một nghiên cứu tại Ấn Độ cũng cho thấy rằng tiểng ồn phát ra tại một nhà máy xay xát luôn giao động ở mức 78 - 92dB và sức khỏe của khoảng $26 \%$ công nhân tại đây bị ảnh hưởng bởi tiếng ồn(8).

Phòng ngừa suy giảm và mất thính lực cho người lao động cần phải được phát hiên sớm và can thiệp sớm là việc rất quan trọng để đảm bảo chất lượng cuộc sống của công nhân. Có nhiều biện pháp hố trợ phòng ngừa ĐNN như sử dụng bảo hộ lao động (BHLĐ) khi tiễp xúc với tiếng ôn, thường xuyên kiểm tra quan trắc tiếng ồn nhằm kiểm soát thời gian tiếp xúc với tiêng ôn trong mức độ cho phép (9).

Nghiên cứuđược tiến hành với mong muốn tìm hiểu thực trạng tiêng ồn tại nhà máy và thực hành phòng ngừa điếc nghề nghiệp của người lao động tại đây.

\section{II. ĐỐI TƯợNG VÀ PHƯƠNG PHÁP NGHIÊN CỨU 2.1. Đối tượng nghiên cứu}

- Môi trường lao động của Nhà máy tinh bột sắn Đồng Xuân, huyện Đồng Xuân, tỉnh Phú Yên khi đang hoạt động.

- Tất cả người lao động tham gia sản xuất trực tiếp tại Nhà máy tinh bột sắn Đồng Xuân, huyện Đồng Xuân, tỉnh Phú Yên đồng ý tham gia nghiên cứu

2.1. Thời gian và địa điểm nghiên cứu. Từ tháng 11 năm 2017 đến tháng 6 năm 2018 tại Nhà máy tinh bột sắn Đồng Xuân, huyện Đồng Xuân, tỉnh Phú Yên.

2.2. Thiết kế nghiên cứu. Nghiên cứu cắt ngang.

2.3. Cỡ mẫu

2.3.1. Cỡ mẫu kiến thức - thái độ - thực hành: Chọn mẫu toàn bộ người lao động trực tiếp tham gia sản xuất tại Nhà máy gồm có 125 công nhân.

2.3.2 Cõ̃ mẫu về tiếng ồn. Tại nhà máy tinh bột sắn Đồng Xuân có hai khu làm việc riêng biệt nhau là khu sản xuất và khu hành chính. Theo kết quả quan trắc môi trường năm 2016 của Trung tâm $Y$ tế dự phòng tỉnh Phú Yên thì tiếng ôn cao chủ yếu từ khu vực sản xuất, ảnh hưởng trực tiếp đến người lao động; khu hành chính cách xa và ít bị ảnh hưởng nguồn gây ồn từ khu sản xuất.

Số mẫu về tiếng ồn chung đã được đo là 26, trong số các vị trí đo, các vị trí có mức tiếng ồn vượt tiêu chuẩn cho phép sẽ sử dụng mẫu tiếng ôn theo dải tần. Tổng số 13 mẫu tiếng ồn theo dải tần đã được đo năm 2016 tại các khu vực trong nhà máy đã được đưa vào phân tích trong nghiên cứu này.

2.4. Phương pháp chọn mẫu. Chọn mẫu toàn bộ người lao động tại Nhà máy.

Mẫu tiếng ồn được lựa chọn đại diện cho quy trình sản xuất.

\subsection{Phương pháp thu thâp số liệu}

2.5.1. Thu thập số liệu về kiến thức - thái độ - thức hành

Tất cả công nhân trực tiếp tham gia sản xuất đủ tiêu chuẩn chọn mẫu trong thời gian thu thập số liệu sẽ được mời tham gia vào nghiên cứu.

Giải thích trực tiếp, rõ ràng mục đích nghiên cứu cho đối tượng nghiên cứu. Nếu người lao động đồng ý tham gia nghiên cứu thì ký tên vào phiếu đồng ý tham gia nghiên cứu

Công cụ thu thập số liệu: bộ câu hỏi phát vấn cấu trúc

2.5.2 Thu thâp số liệu về thực hành phòng ngừa điếc nghề nghiệp

Phương tiện thu thập thông tin: sử dụng bảng kiểm quan sát thực hành tất cả người lao động trực tiếp trong các phân xưởng sản xuất có 
tiếp xúc trực tiếp với tiếng ồn.

Thời điểm quan sát: quan sát trực tiếp khi người lao động đang làm việc. Mỗi người lao động quan sát 01 lần (01 quan sát x 125 công nhân $=125$ quan sát).

\subsubsection{Thu thập số liệu về tiếng ồn}

Phương tiện: quan trắc cường độ tiếng ồn bằng máy Bruel \& Kjaer, Control IEC 61672-1, Cirrus 172B.

Quan trắc cường độ tiếng ồn theo dải tần bằng máy Bruel \& Kjaer, Cirrus.

2.6. Các biến số nghiên cứu. Biến số về cường độ tiếng ồn chung và cường độ tiếng ồn theo dải tần. Biến số về thông tin chung của người lao động

Các biến số về thực hành của người lao động về dự phòng điếc nghề nghiệp

2.7. Các khái niệm - thước đo - tiêu chuẩn đánh giá

Tiếng ồn: Sử dụng bảng quy chuẩn kỹ thuật quốc gia số 24:2016/BYT được ban hành kèm Thông tư số 24/2016/TT-BYT ngày 30/6/2016 của Bộ Y tế. Giá trị đo vượt quá giá trị được quy định trong quy chuẩn này được tính là không đạt chỉ tiêu an toàn vệ sinh lao động.
2.8. Xử lý và phân tích số liệu

- Số liệu được mã hóa trước khi nhập và lưu trữ bằng phần mềm Excel.

- Dữ liệu được phân tích bằng chương trình SPSS 16.0 (Statistical Package for the Social Sciences 16.0).

- Các biến số định tính được mô tả bằng bảng phân phối tần số (n), tỷ lệ (\%).

- Các biến số định lượng được mô tả bằng giá trị trung bình \pm độ lệch chuẩn.

2.9. Vấn đề đạo đức trong nghiên cứu. Đề tài được tiến hành sau khiđược sự cho phép thu thập dữ liệu từ Ban lãnh đạo Nhà máy tinh bột sắn Đồng Xuân, Phú Yên.

Đề cương của nghiên cứu này đã được sự phê duyệt và cho phép từ Hội đồng nghiên cứu khoa học của Đại học Y tế công cộng theo các quy định về y đức trong nghiên cứu khoa học (Quyết định số 036/2018/YTCC-HĐ3 ngày 29/01/2018).

\section{KẾT QUẢ NGHIÊN CỨU}

3.1. Thực trạng tiếng ồn tại nhà máy

Cường độ tiếng ồn chung

Bảng 3.1.Kêt quả đo cường độ ôn chung

\begin{tabular}{|c|c|c|c|c|}
\hline \multirow{3}{*}{ TT1 } & \multirow{3}{*}{ TT2 } & \multirow{2}{*}{ Vị trí quan trắc } & \multicolumn{2}{|c|}{ Kết quả quan trăc } \\
\hline & & & Đạt GHCP & Không đạt GHCP \\
\hline & & Mức giới hạn cho phép & \multicolumn{2}{|c|}{$\leq 85 d B A$} \\
\hline \multirow[t]{7}{*}{ (1) } & & KV nguyên liệu đâuu vào & & \\
\hline & 1 & Đầu KV nguyên liệu trước cửa nhà máy & 84 & \\
\hline & 2 & Tại VT CN đang VH máy rửa củ & & 86 \\
\hline & 3 & Giữa KV máy dập & & 88 \\
\hline & 4 & Tại các VT CN đang VH máy mài & & 90 \\
\hline & 5 & Giữa KV máy mài & & 87 \\
\hline & 6 & Tại các VT CN đang VH máy tách xác & & 91 \\
\hline \multirow[t]{5}{*}{ (2) } & & KV phân ly & & \\
\hline & 7 & Giữa KV phân ly cấp 1 & & 89 \\
\hline & 8 & Tại VT CN đang VH máy phân ly cấp 1 & & 92 \\
\hline & 9 & Giữa KV phân ly cấp 2 & & 90 \\
\hline & 10 & Tại VT CN đang VH máy phân ly cấp 2 & & 93 \\
\hline \multirow[t]{3}{*}{ (3) } & & KV ly tâm & & \\
\hline & 11 & Tại VT CN đang VH 4 máy ly tâm & & 89 \\
\hline & 12 & Tại VT giữa khu ly tâm & & 87 \\
\hline \multirow[t]{3}{*}{ (4) } & & KV sấy & & \\
\hline & 13 & Tại VTCN đang V̈H máy sấy & & 87 \\
\hline & 14 & Giữa KV sấy & & 86 \\
\hline \multirow{3}{*}{ (5) } & & KV đóng bao thành phấm & & \\
\hline & 15 & Tại các VT CN đang thao tác đóng bao & 82 & \\
\hline & 16 & Giữa kho thành phẩm & 80 & \\
\hline \multirow[t]{2}{*}{$(6)$} & & KV lò đốt & & \\
\hline & 17 & Tại các VT CN đang VH lò đốt & 83 & \\
\hline (7) & & KV máy tách xác & & \\
\hline
\end{tabular}




\begin{tabular}{|c|c|c|c|c|}
\hline & 18 & Giữa KV máy tách xác cấp 1 & 82 & \\
\hline & 19 & Tại các VT CN VH hệ thống tách xác cấp 1 & 84 & \\
\hline & 20 & Giữa KV máy tách xác cấp 2 & 83 & \\
\hline \multirow{2}{*}{ (8) } & & KV sây bã & & \\
\hline & 21 & Giữa KV sấy bã & 79 & \\
\hline \multirow[t]{2}{*}{ (9) } & & Phòng điều khiến trung tâm & & \\
\hline & 22 & Giữa phòng điều khiến điện trung tâm & 82 & \\
\hline \multirow[t]{3}{*}{ (10) } & & KV đóng bao bã thành phấm & & \\
\hline & 23 & Tại VT CN đóng bao bã thành phấm & 83 & \\
\hline & 24 & Tại VT giữa kho thành phấm bã & 80 & \\
\hline \multirow[t]{3}{*}{ (11) } & & Xưởng cơ khí & & \\
\hline & 25 & Tại VT CN đang VH máy khoan & & 88 \\
\hline & 26 & Giữa xưởng cơ khí & 74 & \\
\hline
\end{tabular}

Có 14/26 (53,9\%) mẫu có cường độ tiễng ồn vượt cho phép theo quy định, trong đó mức ôn cao nhất là 93dBA tại khu vực máy phân ly cấp 2, mức ồn cao thứ nhì đo được là 92dBA tại khu vực phân ly cấp 1 . Như vậy, mức độ ô nhiễm tiếng ồn nguy hiểm cao nhất tập trung tại các khu vực máy phân ly vận hành.

Cường độ tiếng ồn dải tần tại 8 tần số

Bảng 3.2. Kết quả đo cường độ ồn theo dải tần

\begin{tabular}{|c|c|c|c|c|c|c|c|c|c|c|}
\hline \multirow{3}{*}{$\pi$} & \multirow{3}{*}{$\begin{array}{c}\text { TT } \\
\mathbf{2}\end{array}$} & \multirow[t]{2}{*}{ VỊ TRÍ QUAN TRẮC } & \multicolumn{8}{|c|}{$\begin{array}{c}\text { Cường độ tiếng ồn theo dải tân - tại các } \\
\text { tân số (Hz) }\end{array}$} \\
\hline & & & 63 & 125 & 250 & 500 & 1000 & 2000 & 4000 & 8000 \\
\hline & & Mức giới han cho phép & 99 & 92 & 86 & 83 & 80 & 78 & 76 & 74 \\
\hline (1) & & KV nguyên liệu đầu vào & & & & & & & & \\
\hline & 1 & Tại VT CN đang V̈H máy rửa củ & 88 & 86 & 82 & 80 & 78 & 76 & 72 & 64 \\
\hline & 2 & Giữa KV máy dập & 90 & 88 & 86 & 83 & 80 & 78 & 74 & 70 \\
\hline & 3 & Tại các VT CN đang VH máy mài & 92 & 90 & 87 & 84 & 82 & 80 & 76 & 74 \\
\hline & 4 & Giữa KV máy mài & 89 & 86 & 84 & 82 & 80 & 78 & 74 & 70 \\
\hline & 5 & Tai VT CN đang VH máy tách xác & 96 & 93 & 88 & 85 & 82 & 78 & 76 & 74 \\
\hline (2) & & KV phân ly & & & & & & & & \\
\hline & 6 & Giữa KV phân ly cấp 1 & 92 & 90 & 87 & 84 & 80 & 78 & 76 & 72 \\
\hline & 7 & Tại VT CN đang VH máy phân ly cấp 1 & 94 & 92 & 88 & 85 & 82 & 78 & 76 & 74 \\
\hline & 8 & Giữa KV phân ly cấp 2 & 92 & 90 & 87 & 84 & 82 & 80 & 76 & 74 \\
\hline & 9 & Tai VT CN đang VH máy phân ly cấp 2 & 96 & 94 & 90 & 86 & 84 & 80 & 78 & 76 \\
\hline (3) & & KV ly tâm & & & & & & & & \\
\hline & 10 & Tai VT CN đang VH 4 máy ly tâm & 92 & 88 & 86 & 83 & 80 & 78 & 74 & 72 \\
\hline & 11 & Tại VT giữa khu ly tấm & 89 & 86 & 84 & 82 & 80 & 78 & 74 & 70 \\
\hline (4) & & & & & & & & & & \\
\hline & 12 & Tại VTCN đang vận hành máy sấy & 89 & 87 & 84 & 82 & 80 & 78 & 74 & 70 \\
\hline & 13 & Giữa KV sấy & 88 & 86 & 82 & 80 & 78 & 76 & 72 & 64 \\
\hline
\end{tabular}

Kết quả quan trắc cho thấy có $6 / 13(46,2 \%)$ mầu không đạt GHCP tập trung chủ yếu tại khu vực các máy phân ly tại các dải tần số $250-2000 \mathrm{~Hz}$. Đặc biệt khu vực máy phân ly cấp 2 mức ồn theo dải tần số vượt QCVN cho phép lên đến $8000 \mathrm{~Hz}$. Mức độ ồn khu vực máy phân ly cấp 2 QCVN cho phép cao nhất tại dải tần $250 \mathrm{~Hz}$ và $1000 \mathrm{~Hz}$ là $4 \mathrm{dBA}$.

\subsection{Thực hành}

Bảng 3.3 Thực hành của NLÐ về các biện pháp phòng ngừa ĐNN

\begin{tabular}{|c|c|c|}
\hline \multirow{2}{*}{ Nội dung } & \multicolumn{2}{|c|}{ Thực hành } \\
\hline & Có [n (\%)] & Không [n (\%)] \\
\hline $\begin{array}{c}\text { Mang theo trang bị phương tiện bảo hộ lao động khi vào ca } \\
\text { làm việc }\end{array}$ & $125(100)$ & $0(0)$ \\
\hline Tham gia học về ATVSLD & $123(98,4)$ & $2(1,6)$ \\
\hline $\begin{array}{c}\text { Thường xuyên sử dụng phương tiện bảo hộ lao động khi } \\
\text { làm viêcc }\end{array}$ & $56(44,8)$ & $69(55,2)$ \\
\hline Sử dụng nút tai/chụp tai để bảo vệ & $100(80)$ & $25(20)$ \\
\hline
\end{tabular}




\begin{tabular}{|c|c|c|}
\hline Sử dụng phương tiện chống ôn cả 2 bên tai & $55(44)$ & $70(56)$ \\
\hline Cảm giác ù tai, nghe kém & $45(36)$ & $80(64)$ \\
\hline Nghì giữa ca làm việc & $121(96,8)$ & $4(3,2)$ \\
\hline Nghỉ giữa giờ làm việc tại nơi yên tĩnh ít ồn & $67(52,8)$ & $58(47,2)$ \\
\hline Khám bệnh khi có dấu hiệu nghe kém & $66(52,8)$ & $59(47,2)$ \\
\hline Tham gia khám sức khỏe định kỳ & $125(100)$ & $0(0)$ \\
\hline
\end{tabular}

100\% NLĐ có mang theo thiết bị bảo hộ lao động khi vào ca làm việc, $100 \%$ NLĐ tham gia khám sức khỏe định kỳ và $98,4 \%$ NLĐ tham gia khóa học về ATVSLĐ do nhà máy tổ chức. Măc dù có $80 \%$ NLĐ sử dụng nút tai/chụp tai để bảo vê nhưng chỉ có $44,8 \%$ NLĐ sử dụng phương tiện bảo hộ lao động một cách thường xuyên, $44 \%$ NLĐ sử dụng phương tiện chống ồn cho cá 2 tai. Tỷ lệ NLE் có cảm giác ù tai nghe kém là $36 \%$ và $52,8 \%$ NLĐ đi khám bệnh khi có dấu hiệu rối loạn thính lực. 96,8\% NLĐ có nghỉ giữa ca làm việc tuy nhiên chỉ có $52,8 \%$ NLĐ nghỉ giữa ca làm việc tại những nơi yên tĩnh, ít ôn. ĐNN.

Chỉ có 52,8\% NLĐ thực hành tốt về dự phòng

\section{BÀN LUẬN}

Qua khảo sát, quan trắc tiếng ồn tại nhà máy Tinh bột Đồng Xuân, huyện Đồng Xuân tỉnh Phú Yên chúng tôi ghi nhận có 14/26 mẫu có cường độ tiếng ồn chung vượt quá giới hạn tiêu chuẩn vệ sinh cho phép hiện nay, chiếm tỷ lệ $53,9 \%$ và 46,2\% mẫu không đạt giới hạn cho phép khi phân tích tiếng ồn theo dải tần. Cường độ tiếng ồn vượt từ $1-8 \mathrm{dBA}$ so với mức tối đa cho phép của Bộ y tế hiện nay là $85 \mathrm{dBA}$. Kết quả này tương tự kết quả nghiên cứu của tác giả Hồ Xuân Vũ và cộng sự (2009) thực hiện tại Huế là $57,6 \%$, hay nghiên cứu của tác giả Huỳnh Chung và cộng sự (2014) có 49,6\% số mẫu ồn vượt tiêu chuẩn cho phép, độ ồn vượt tiêu chuẩn là $6 \mathrm{dBA}$.

Nguồn ồn chủ yếu tại nhà máy này là nguồn ôn điểm, một số khu vực phát ra tiếng ồn vượt ngưỡng giới hạn cho phép là khu vực nhập liệu đầu vào $(87,67 \pm 2,58 \mathrm{dBA})$, khu vực phân ly $(91$ $\pm 1,83 \mathrm{dBA})$, khu vực ly tâm $(88 \pm 1,41 \mathrm{dBA})$ trong đó nguồn ồn phát ra cao nhất tại khu vực máy phân ly cấp 2 hoạt động, phát ra tiếng ồn có cường độ $93 \mathrm{dBA}$. Qua phân tích ở trên cho thấy cần đặc biệt lưu ý trong việc bố trí, sắp xếp luân chuyển công nhân làm việc tại các vị trí trên một cách hợp lý, đồng thời chú ý giờ nghỉ giữa ca, giám sát việc thực hiện các biện pháp hạn chế tác hại của nguồn ồn của NLĐ nhằm hạn chế tác hại của tiếng ồn và phòng ngừa ĐNN.

Thực hành của người lao động về phòng ngừa điếc nghề nghiệp. Tỷ lệ NLĐ có thực hành đúng về phòng ngừa ĐNN trong nghiền cứu của chúng tôi chưa cao, chỉ có $52,8 \%$. Có 2 hành động mà $100 \%$ NLD thực hiện đúng đó là luôn mang theo phương tiện bảo hộ lao động khi vào ca làm việc và tham gia khám sức khỏe định kỳ do nhà máy tổ chức nhưng ngược lại, chỉ có $52,8 \%$ NLĐ đi khám bệnh khi có dấu hiệu rối loạn thính giác. Có $96,8 \%$ công nhân có nghỉ giữa ca làm việc nhưng chỉ có $52,8 \%$ công nhân chọn chỗ nghỉ giữa giờ tại nơi yên tĩnh, ít ồn. Nội dung này chúng tôi khảo sát được cao hơn so với nghiên cứu của tác giả Huỳnh Chung và cộng sự (2014), tỷ lệ này lần lượt là $44,1 \%$ và $38 \%$. Tuy vậy, chúng tôi nhận thấy chỉ có $44,8 \%$ công nhân sử dụng thiết bị chống ồn một cách thường xuyên và $44 \%$ NLĐ sử dụng thiết bị này cho cả 2 bên tai. Kết quả này của chúng tôi gân giống với kết quả khảo sát được trong nghiên cứu Huỳnh Chung và cộng sự (2014) ghi nhận chỉ có 31,5\% NLĐ đeo thiết bị bảo vệ tai đúng cách khi làm việc... Đây là một trong những lưu ý và bằng chứng quan trọng để lập kế hoạch tập huấn, tuyên truyền giáo duc sức khỏe giúp NLĐ sử dụng một cách có hiệu quả các thiết bị bảo vệ tai khỏi tác hại của tiếng ổn song song với việc cung cấp, trang bị phương tiện bảo hộ lao động cho NLĐ.

\section{KẾT LUẬN}

Tại nhà máy chế biến tinh bột sắn, kết quả đo tiếng ồn cho thấycường độ tiếng ồn chung tại nhà máy giao động trong khoảng $74-93 \mathrm{dBA}$, có $53,9 \%$ mẫu tiếng ồn vượt giới hạn cho phép. Khu vực phát ra tiếng ồn cao nhất là khu vực phân ly với mức ồn trung bình là $91 \pm 1,83 \mathrm{dBA}$. Có tới 47,2\% NLĐ thực hành chưa tốt về phòng ngừa điếc nghề nghiệp.

\section{TÀI LIẸU THAM KHẢO}

1. Béatrice Duthey (2013), "Background paper 6.21 hearing loss", Geneva: WHO Int.

2. Rena H Glaser (1997), "Preventing Occupational Hearing Loss-A Practical Guide", Ear and Hearing. 18(4), page. 352-353.

3. Dinh Xuan Ngon (2015), "Immprovement of policy on occupational saferty and health. From Policy Development to Implementation Measures", Japan Industrial Safety \& Health Association.

4. World Health Organization (2016), WHO global estimates on prevalence of hearing loss, http:// www. who. int/pbd/deafness/WHO GE HL. pdf. 
5. World Health Organization (2017), WHO methods and data sources for global burden of disease estimates 2000-2015, Department of Information, Evidence and Research WHO, Geneva.

6. Theo Vos \& et al (2015), "Global, regional, and national incidence, prevalence, and years lived with disability for 301 acute and chronic diseases and injuries in 188 countries, 1990-2013: a systematic analysis for the Global Burden of Disease Study 2013", The Lancet. 386(9995), page. 743-800.
7. Elizabeth A Masterson (2016), "Hearing impairment among noise-exposed WorkersUnited States, 2003-2012", MMWR. Morbidity and mortality weekly report. 65 .

8. World Health Organization (2015), "Hearing loss due to recreational exposure to loud sounds: a review".

9. Đố Văn Hàm (2007), "Tiếng ồn trong sản xuất và điếc nghề nghiêp", trong Đố Văn Hàm, chủ biên Sức khỏe nghề nghiệp, Nhà xuất bản $Y$ học Hà Nội, Hà Nội.

\section{NGHIÊN CỨU ĐôC TÍNH VÀ ẢNH HƯởNG CỦA MÔTT Số LOÀI NẤM ĐộC THƯờnG GĂP TAI TİNH VĨNH PHÚC LỀN MộT SỐ CHİ TIÊU HÓA SINH TRỂN ĐộNG VẬT THỰC NGHIỆM}

\section{TÓM TẮT}

Các vụ ngộ độc nấm độc thường xuyên xảy ra ở các tỉnh miền Bắc Việt Nam. Kết quả nghiên cứu trên động vật cho thấy $L_{50}$ qua đường tiều hoá đối với nấm khồ xốp gây nôn là $4,912 \mathrm{~g} / \mathrm{kg}$ thể trọng, đối với nấm tươi là 42,126g/kg thể trọng. Hoạt độ ALT, GGT trong máu thỏ bị ngộ độc nấm xốp gây nổn tăng có ý nghĩa thống kê ở ngày thứ 1 sau ngộ độc so với trước khi bị ngộ độc $(p<0,001)$. LD50 qua đường tiêu hóa của nấm ô tán trắng phiến xanh đối với nấm khô là $3,658 \mathrm{~g} / \mathrm{kg}$ thể trọng, đối với nấm tươi là $34,913 \mathrm{~g} / \mathrm{kg}$ thể trọng. Hoạt độ ALT trong máu thỏ bị ngộ độc nấm ô tán trănng phiến xanh tăng có ý nghĩa thống kê ở ngày thứ 1 sau ngộ độc so với trước khi bi ngô đôc $(p<0,001)$. Hoạt độ GGT tăng không có ý nghĩa thống kê ở tất cả các thời điểm nghiên cứu.

Tư khóa: Độc tính cấp tính (LD50), nấm xốp gây nôn, nấm ô tán trắng phiến xanh, chỉ tiêu hóa sinh, động vật thực nghiệm

\section{SUMMARY}

\section{STUDYING ON TOXICITY AND} EFECTIVENESS OF SOME TYPICAL POISONOUS MUSHROOMS IN VINH PHUC PROVINCE SEED EXTRACT ON

\section{BIOCHEMISTRY OF ANIMAL MODEL}

Case series of poisonous mushrooms and plants often occured in Northern provinces of Vietnam. Results of animal studies showed that LD50 of dried Russula emetica mushroom passed through the gastrointestinal tract was $4.912 \mathrm{~g} / \mathrm{kg} \mathrm{BW}$, fresh Russula emetica mushroom was $42.126 \mathrm{~g} / \mathrm{kg}$ BW. The activity of ALT, GGT in rabbit poisoned was significantly higher on day 1 after poisoning than before exposure

*Hoc viên Quân y

Chịu trách nhiệm chính: Hoàng Anh Tuấn

Email: anhtuank20@gmail.com

Ngày nhận bài: 11.3.2021

Ngày phản biên khoa hoc: 30.4.2021

Ngày duyệt bài: 13.5.2021

\section{Hoàng Anh Tuấn*, Hoàng Đắc Thăng*}

( $p$ <0.001). LD50 of dried and fresh Chlorophyllum molybdites mushroom was $3.658 \mathrm{~g} / \mathrm{kg}$ and 34.913 $\mathrm{g} / \mathrm{kg}$ BW, respectively. The activity of ALT in rabbit poisoned was significantly higher on day 1 after poisoning than before exposure $(p<0.001)$. The GGT activity increased with no significance difference in all the point's time of the study.

Key words: Toxicity, Rusulla emetica, Chlorophyllum molybdites, biochemical, animal

\section{I. ĐẶT VẤN ĐỀ}

Việt Nam là một nước có nhiều loài thực vật độc và nấm độc. Các trường hợp ngộ độc nấm độc ở nước ta thường xuyên xảy ra tại các tỉnh có nhiều rừng. Trong những năm gần đây, tại Vĩnh Phúc đã xảy ra nhiều vụ ngộ độc nấm độc. Ngộ độc nấm độc thường xảy ra ở các cư dân sống ở vùng rừng núi, dân trí thấp, đời sống người dân còn gặp nhiều khó khăn và hậu quả để lại thường rất nặng nê. Nhiêuu trường hợp cả gia đình bị ngộ độc, tử vong nhiêu người trong cùng một gia đình. Có trường hợp cả gia đình phải nằm viện, chi phí cho điêu trị rất tốn kém.

Đã có một số công trình nghiên cứu về độc tính của nấm độc nhưng còn có nhiêu ý kiến trái ngược nhau. Vì vậy, chúng tôi tiến hành nghiên cứu đề tài này với mục tiêu nghiên cứu xác định độc tính cấp tính (LD50) và đánh giá ảnh hưởng của một số loài nấm độc thường gặp trên địa bàn tỉnh Vĩnh Phúc (thu hái tại thị trấn Tam Đảo, huyện Tam Đảo tỉnh Vĩnh Phúc) lên các chỉ tiêu hóa sinh trên động vật thực nghiệm.

\section{II. ĐỐI TƯợNG VÀ PHƯƠNG PHÁP NGHIÊN CỨU \\ 2.1. Đối tượng nghiên cứu \\ *Chuột nhắt trắng: 480 chuột khoẻ mạnh, trọng lượing trung bình $20 \pm 0,2$ gam (không tính số chuột nhắt trắng dùng cho thăm dò liều}

